\title{
ANÁlise dA COMUNICAÇÃO VERBAL E NÃO-VERBAL DE CRIANÇAS COM DEFICIENCIA VISUAL DURANTE INTERAÇÃO COM A MÃE ${ }^{1}$ ANALYSIS OF THE VERBAL AND NON-VERBAL COMMUNICATION OF CHILDREN WITH VISUAL IMPAIRMENT DURING INTERACTION WITH THEIR MOTHERS

\author{
Jáima Pinheiro de OLIVEIRA² \\ Susi Lippi MARQUES ${ }^{3}$
}

RESUMO: a importância da linguagem para as crianças deficientes visuais é indiscutível, pois se trata da principal forma de promover sua interação social, além de ser fundamental na mediação de todo o seu processo de aprendizagem. Nesse sentido, o objetivo deste estudo foi descrever o desempenho pragmático da linguagem de crianças cegas, com baixa visão e com visão normal, analisando as particularidades da interação entre mãecriança em contextos livre e planejado. Participaram do estudo seis crianças: duas cegas, duas com baixa visão e duas com visão normal, selecionadas a partir de critérios específicos. Foram realizadas duas filmagens de cada díade em ambiente familiar, sendo uma em situação de brinquedo livre e outra em situação planejada. A análise contemplou a comunicação verbal e não-verbal das crianças e foi realizada por meio da categorização funcional, com protocolo previamente elaborado e aferido por juízes, no qual continham os meios, bem como as funções pragmáticas emitidas pelos participantes. Os dados revelaram que houve um predomínio do meio comunicativo verbal, tanto em situação livre como planejada. De maneira geral, os resultados do estudo indicaram que embora houvesse particularidades durante o seu uso, a linguagem das crianças deficientes visuais não se apresentou deficitária em relação a de crianças com visão normal. Além disso, as mães das crianças cegas e com baixa visão utilizaram estratégias que favoreceram esse desempenho, como descrições do ambiente, indicações e localizações de objetos durante a interação, tanto em contexto livre, quanto planejado.

PALAVRAS-CHAVE: cegueira; visão subnormal; desenvolvimento da linguagem; interação mãe-criança; necessidades especiais.

\begin{abstract}
: the importance of the language for the visual impairment children is unquestionable because it is a way to promote their social interaction. Besides, it is fundamental in the mediation of the learning process. In this context, the objective of this study was to compare the pragmatic performance of the language between blind children, with low vision capacity and children with normal vision and, therefore, to analyze the particularities of the maternal communication during the interaction within free and planned contexts. Six children participated in the study: two blind; two with low vision capacity and; two with normal vision, who were selected from specific criteria. Two recordings of each were carried out in the familiar environment: free and planned situations. The analysis was performed by means of functional characterization of the verbal and non-verbal communication of the children with their mothers. The data showed that the verbal communicative resources were predominant in both free and planned situations. Overall, the results of this study indicate that although there were particularities during its use, the language of the visual impairment children does not present deficit in relation to the one of those with normal vision. Moreover, the mothers of the blind children and with low vision capacity used strategies such as descriptions of the environment, indications and localization of objects during their interactions that favored their performance.
\end{abstract}

KEYWORDS: blindness; low vision; language development; mother-children interaction; special needs.

\footnotetext{
${ }^{1}$ As autoras agradecem o apoio financeiro da CAPES (Coordenação de Aperfeiçoamento de Pessoal de Nível Superior) pela concessão de bolsa de mestrado durante o ano de 2003 e à Escola Anexa ao Instituto dos Cegos do Brasil Central/MG.

${ }^{2}$ Fonoaudióloga; Docente do Departamento de Fonoaudiologia da Universidade Estadual do Centro-Oeste UNICENTRO, Campus de Irati/PR; Doutoranda do Programa de Pós-graduação em Educação Especial da Universidade Federal de São Carlos/SP. jaimapo@yahoo.com.br

${ }^{3}$ Orientadora; Docente do Departamento de Psicologia e do Programa de Pós-graduação em Educação Especial da Universidade Federal de São Carlos/SP (UFSCar) - susilmo@power.ufscar.br
} 


\section{LINGUAGEM E DEFICIÊNCIA VISUAL}

Sabe-se que as primeiras relações, em especial a interação entre mãebebê, são fundamentais, senão decisivas, em todo o processo de aquisição e desenvolvimento da linguagem. Especificamente em relação às crianças com alterações no desenvolvimento, sejam estas físicas, mentais, sensoriais ou ainda globais, essa interação pode ser dificultada em função de uma baixa ou ausência de responsividade por parte da criança (SCHERMANN, 2001).

Dentro deste contexto, a ausência da informação visual é indicada como responsável por atrasos e alterações durante as fases iniciais da aquisição da linguagem em crianças com deficiência visual em decorrência de outros fatores que permeiam esse processo. Como, por exemplo, o desenvolvimento motor e cognitivo. Alguns autores ressaltaram este fato ao dizerem que a visão é a base da maioria dos aprendizados humanos e na ausência desta durante a primeira infância aspectos cognitivos, conceituais e de linguagem são alterados em estágios sensíveis do desenvolvimento infantil (FINELLO; HANSON; KEKELIS, 1994). A importância da visão no desenvolvimento de habilidades motoras é evidenciada por sua grande influência no desenvolvimento cognitivo da criança, sendo que muitas dessas habilidades são aprendidas por meio da imitação e estimulação visual. Isso, por sua vez, influenciaria de modo significativo o desenvolvimento lingüístico das crianças com deficiência visual.

A literatura indica, ainda, observações quanto aos comportamentos específicos envolvidos em estágios pré-lingüísticos, evidenciando uma menor freqüência do balbucio por parte destas crianças quando comparadas às crianças com visão normal. Dentre as explicações para tal diferença, está a de que a criança deficiente visual normalmente fica esperando por estímulos dos adultos para emitir vocalizações. Por assim ser, esse atraso, segundo alguns autores, poderia ser responsável, em segunda instância, pela maior freqüência de distúrbios articulatórios em crianças cegas se comparadas àquelas com visão normal (MILLS, 2002).

É possível que a informação visual tenha nítida vantagem para a criança com visão normal durante a emissão de padrões fonéticos que são observáveis (sons bilabiais, por exemplo), pois elas apresentam um aperfeiçoamento maior em relação a esses movimentos articulatórios se comparadas às crianças com déficits visuais. Estas últimas cometem erros com maior freqüência durante as emissões o que, por sua vez, requer em alguns casos a intervenção específica não só em relação aos padrões de fala, mas também em relação ao aparelho motor oral e funções neurovegetativas, ainda que algumas alterações possam estar associadas também a hábitos orais nocivos, como o uso prolongado de chupeta e mamadeira (BRAGA; OLIVEIRA, 2000).

No que se refere ao aspecto de conteúdo da linguagem, uma pesquisa específica sobre o tema indicou a importância do desenvolvimento cognitivo e pragmático da linguagem das crianças deficientes visuais para compreendê-lo (DIMCOVIC; TOBIN, 1995). O estudo teve como objetivo analisar como essas 
crianças percebiam características importantes como forma, tamanho de objetos e, também, como usavam a linguagem e, conseqüentemente, coordenavam esses dois processos. O procedimento constou de uma base verbal e outra figurativa. Os resultados, segundo os autores (DIMCOVIC; TOBIN, 1995), foram abaixo do esperado, pois algumas crianças não compreendiam as tarefas solicitadas. Dentre as conclusões do estudo, houve destaque para a ligação entre o uso da linguagem dos participantes e o conhecimento conceitual que eles possuíam, bem como a importância do ambiente na sua promoção lexical.

Já em relação ao uso da linguagem, a literatura é muito controversa, sendo os debates ampliados quando o tema tem como foco crianças cegas. Analisando os aspectos pragmáticos da linguagem em crianças deficientes visuais, com diferentes graus de comprometimento, alguns autores observaram que essas crianças não produziam muitas variações de conceito e quando utilizavam expressões para se referirem a alguma ação não iam além das próprias (ANDERSEN; DUNLEA; KEKELIS, 1984). Também foi destacada a dificuldade que tais crianças possuíam para descrever acontecimentos externos, atribuindo esses comportamentos à falta do componente visual.

Em contrapartida, um outro estudo analisou tais aspectos tendo como amostra quatro crianças no início da aquisição da linguagem, sendo três deficientes visuais com diferentes graus de comprometimento e uma com visão normal. Os resultados desse estudo mostraram que houve um elevado uso da linguagem, por parte das crianças cegas e com baixa visão, para relatarem suas próprias ações, estados, sentimentos e intenções. Tal atuação poderia ser uma maneira desses sujeitos regularem e planejarem seus comportamentos (PEREZ-PEREIRA; CASTRO, 1992). Houve também uma escassez de categorias que indicassem oferta de objetos ao interlocutor ou outra forma de atrair sua atenção, por parte das crianças cegas. Tal ocorrência não foi observada com o sujeito que possuía baixa visão. Tais resultados foram atribuídos ao fato desse sujeito estar utilizando uma estratégia para estabelecer contato externo.

Um outro resultado observado no mesmo estudo foi o grande uso de categorias descritivas, por parte desse sujeito com baixa visão, utilizando sua linguagem para descrever objetos, localizá-los e citar propriedades dos mesmos (PEREZ-PEREIRA; CASTRO, 1992). Esse comportamento não ocorreu com as crianças que não tinham resíduo visual, ou ocorriam de maneira menos significativa, enquanto era freqüente na linguagem do sujeito com visão normal (PEREZ-PEREIRA; CASTRO, 1992). Mesmo com as particularidades em relação à criança cega e as duas com baixa visão os autores concluíram que o uso da linguagem feito por essas crianças poderia ser considerado semelhante ao da criança com visão normal, porém, assim como destaca a maior parte dos estudos, não era possível a generalização desses dados em função da pequena amostra.

Conforme apresentado anteriormente, os estudos parecem concordantes em relação à alta freqüência do uso da linguagem para descrever 
ações, ainda que a maior parte destas seja para se referirem as próprias ações e não aos acontecimentos ou eventos externos. Normalmente as crianças pedem para repetir algum jogo ou brincadeira, ao passo que poderiam solicitar algum objeto do ambiente. Neste sentido, estudos enfocando este problema também encontraram resultados semelhantes ao analisarem os aspectos pragmáticos de uma criança com baixa visão em diferentes tipos de interação, porém, em algumas situações foi constatado o uso de descrições de eventos externos com a ressalva de que o evento descrito estava relacionado a objetos muito próximos da criança e, portanto, a presença deles já era de seu conhecimento durante a interação (OLIVEIRA; BRAGA, 2000).

A categoria perguntas também foi analisada de modo sistemático no repertório de crianças deficientes visuais, tanto em relação à freqüência quanto aos tipos de questões utilizadas e comparou os resultados ao desempenho de crianças com visão normal, verificando que essas funções são mais usadas pelas crianças deficientes visuais, caracterizando-as como importantes formas de obterem informações sobre o ambiente (HUGHES; DOTE-KWAN; DOLENDO, 1999). Em relação aos tipos de perguntas, o autor verificou que crianças com deficiência visual solicitaram ajuda com maior freqüência. E, por fim, um dado importante a respeito do estudo refere-se ao uso de perguntas retóricas emitidas com maior freqüência pelas crianças com visão normal, o que o autor acredita acontecer pelo fato dessas crianças terem mais informações visuais a respeito do ambiente ao contrário das cegas e com baixa visão. De acordo com o pesquisador, alguns desses dados merecem ser melhor investigados, haja vista o quanto as perguntas influenciam nas áreas de comunicação, desenvolvimento cognitivo e de habilidades sociais (HUGHES; DOTE-KWAN; DOLENDO, 1999). Variações de freqüência das perguntas de acordo com as situações (jogos espontâneos, interações familiares, contato com outras pessoas, etc) podem indicar quando a criança tem necessidade de obter informações ou produzir controle sobre elas.

Seguindo esse raciocínio e relacionando-o com as particularidades do processo de aquisição e desenvolvimento da linguagem das crianças com deficiência visual, alguns estudos indicam que é possível, por meio do apoio na interação com suas mães, a utilização de estratégias que substituam alguns comportamentos das crianças com visão normal, durante a mesma fase de desenvolvimento lingüístico, visando de suprir o que outros pesquisadores chamam de déficits (MILLS, 2002). Dentro deste contexto, outras pesquisas encontraram em suas investigações uma maior porcentagem de quebras na interação entre mães de crianças com visão normal comparadas às de crianças cegas (KEKELIS; PRINZ, 1996). Reforçando a idéia precedente relataram que as mães de crianças cegas tendem a iniciar mais conversa, adaptando seus estilos na interação para que esta seja mantida ou prolongada. A esta situação ou condição de contato, na literatura, é referenciada como sendo um sistema alternativo de comunicação, no qual as estratégias não se baseiam na visão. 
A maior parte dos estudos também enfatiza a importância das primeiras interações dessas crianças com suas mães e utilizam observações sistemáticas destas relações para efeito de análise. Além disso, a estimulação em ambiente familiar também é focada sendo sugerido por alguns autores que a interação entre mãecriança seja analisada de modo mais detalhado tanto do ponto de vista positivo quanto negativo considerando que existem comportamentos diretivos das mães que podem trazer conseqüências prejudiciais ao desenvolvimento, particularmente em relação ao desenvolvimento da linguagem (ANDERSEN; DUNLEA; KEKELIS, 1984; SÍGOLO, 1994).

Ao ser analisado o efeito da ausência visual na interação entre crianças cegas e suas mães referiram que, embora a interação dessas mães seja estruturada no sentido de encorajar seus filhos a emitirem funções mais ativas, as mães dessas crianças emitem com menor freqüência, enunciados que encorajam ou aumentam a possibilidade dessas respostas (KEKELIS; ANDERSEN, 1984). Além disso, essas mães, comparadas às de crianças com visão normal, emitem poucas descrições em relação aos objetos, pessoas ou eventos, podendo influenciar o desempenho semântico e pragmático da linguagem e o desenvolvimento cognitivo de modo geral.

Seguindo ainda esses pressupostos, uma investigação centrada na interação verbal de três crianças deficientes visuais e uma com visão normal, com especial atenção para o uso de diretivos maternos, concluiu que não há diferenças significativas entre essas díades (PEREZ-PEREIRA; CONTI-RAMSDEN, 2001). Os autores ressaltaram que a deficiência visual por si mesma não é impeditiva do desenvolvimento da linguagem nessas crianças. A análise pragmática do estudo destacou a alta freqüência do uso de comportamentos não verbais por parte das crianças e, em relação aos comportamentos diretivos das mães, foi observada uma diferença em relação ao estágio inicial de desenvolvimento da linguagem, no qual as mães das crianças deficientes visuais parecem descrever mais o ambiente, o que outros estudos apontam também como fundamental para manter a atenção e participação da criança na interação (PEREZ-PEREIRA; CONTI-RAMSDEN, 2001). Além disso, é extremamente importante a presença desse comportamento, até mesmo para que a criança possa responder a outras solicitações que poderão surgir ao longo da interação.

Por se tratar de um aspecto fundamental durante o desenvolvimento da linguagem, alguns estudos ao tratarem desse tema, abordam também a questão do ambiente familiar, relatando sobre sua influência não só em relação às crianças com necessidades especiais. Porém, de modo particular, alguns desses estudos delineiam aspectos específicos desse ambiente que parecem ser particularmente significativos para predizer habilidades lingüísticas e intelectuais em relação às crianças cegas (BAIRD; MAYFIELD; BAKER, 1997; HUGHES; DOTE-KWAN; DOLENDO, 1999).

Enfim, a literatura aponta controvérsias nos mais variados aspectos envolvidos no processo de aquisição e desenvolvimento da linguagem em crianças 
com deficiência visual, indicando a necessidade de se dar continuidade a essas investigações. Nesse sentido o presente estudo pretendeu descrever o desempenho pragmático da linguagem desses indivíduos, tendo foco de análise a interação entre crianças deficientes visuais, com visão normal e suas mães. Esta interação foi analisada em diferentes contextos visando buscar subsídios para intervenções educacionais e terapêuticas adequadas.

\section{MÉtodo}

Participantes: participaram desse estudo 6 crianças de ambos os sexos, sendo duas cegas, duas com baixa visão e duas com visão normal, recrutadas a partir de critérios específicos, dentre os quais destacam-se: autorização dos pais para participação voluntária na pesquisa, idade pré-escolar, diagnóstico médico (no caso das crianças deficientes visuais) e não ter sido submetido à intervenção fonoaudiológica durante os primeiros anos de vida. Na Tabela 1 encontra-se a amostra caracterizada. O estudo foi submetido ao Comitê de Ética em Pesquisa (CEP) da instituição, tendo sido aprovado sob protocolo de número 044/2002.

TABELA 1: Descrição dos participantes da pesquisa.

\begin{tabular}{cccccc} 
Sujeitos & Identificação & Sexo & $\begin{array}{c}\text { Idade } \\
\text { cronológica } \\
\text { (em meses) }\end{array}$ & $\begin{array}{c}\text { Diagnóstico } \\
\text { oftalmológico }\end{array}$ & $\begin{array}{c}\text { Recursos ópticos } \\
\text { utilizados }\end{array}$ \\
\hline $\mathbf{1}$ & CCF & F & 66 meses & Cegueira total & Nenhum \\
$\mathbf{2}$ & CCM & M & 72 meses & Cegueira total & Prótese Ocular \\
$\mathbf{3}$ & CBVF & F & 72 meses & Visão subnormal & Lentes corretivas \\
$\mathbf{4}$ & CBVM & M & 72 meses & Visão subnormal & Lentes corretivas \\
$\mathbf{5}$ & CVNF & F & 71 meses & Não se aplica & Não se aplica \\
$\mathbf{6}$ & CVNM & M & 67 meses & Não se aplica & Não se aplica \\
\hline
\end{tabular}

Legenda: CCF - criança cega do sexo feminino; CCM - criança cega do sexo masculino; CBVF criança com baixa visão do sexo feminino; CBVM - criança com baixa visão do sexo masculino; CVNF - criança com visão normal do sexo feminino; CVNM - criança com visão normal do sexo masculino.

Ambiente: as crianças deficientes visuais foram selecionadas na Escola Anexa ao Instituto dos Cegos do Brasil Central - MG, após autorização da instituição e, posteriormente, dos pais ou responsáveis. As partes subseqüentes do estudo foram realizadas em ambiente domiciliar. 
Equipamentos, materiais e instrumentos: utilizou-se para coleta de dados filmadora JVC GR - AX (6X zoom lens/low lux). Além disso, foram utilizados também os seguintes materiais e instrumentos: adaptador para fita VHS TC - 30, papel sulfite A4, jogo de tinta guache com 6 cores (solúvel em água e não tóxico), pincéis $\mathrm{n}^{\circ} 6$ e 8 (grande com cabo de madeira colorido), tubo de cola plástica (90g), toalha pequena, copo plástico, cópias de desenhos impressos ampliados. Os instrumentos utilizados foram: a) roteiro para entrevista de anamnese com a mãe contendo: dados de identificação da criança, de seus familiares, período gestacional, condições pré, peri e pós-natais; informações acerca do desenvolvimento motor geral e específico, lingüístico e cognitivo; dados atuais de comunicação e rotina da criança, dentre outros; b) roteiro para transcrição das filmagens, a partir dos atos comunicativos da criança e da mãe e c) roteiro para categorização pragmática do desempenho comunicativo das crianças.

Procedimento de coleta de dados: foram realizadas duas filmagens de interação mãe-criança em ambiente domiciliar, sendo uma sessão livre e uma planejada. Esse procedimento foi adotado para todas as crianças, atentando-se para o seguinte detalhe: foi realizada uma atividade planejada específica para as crianças cegas (CC) e outra para crianças com baixa visão (CBV). A primeira constou da confecção de um chocalho, utilizando-se para isso um refil de garrafa plástica $(400 \mathrm{ml})$, papel camurça (cor preta), tesoura pequena sem pontas e pequena quantidade de grãos (arroz). Para a segunda atividade, isto é, para as crianças com baixa visão, foi realizada uma atividade de pintura com duas páginas. Em uma página continha oito desenhos e em outra página apenas um, a fim de que mesmo aquelas crianças que possuíssem alteração significativa de campo visual fossem beneficiadas. Os desenhos foram retirados da revista infantil Picolét ${ }^{4}$ Sendo assim, para fins de comparação, foi necessário efetuar três filmagens das crianças com visão normal (1 livre; 1 planejada para crianças cegas; 1 planejada para crianças com baixa visão). Cada filmagem durou em média 20 minutos.

Procedimento de análise de dados: as filmagens foram transcritas na íntegra, considerando também possíveis impressões do pesquisador. Num protocolo, elaborado previamente, foram estabelecidos campos específicos para cada emissão comunicativa transcrita, meio comunicativo utilizado pela criança e pelo interlocutor e, por fim, um campo correspondente à função a ser atribuída a cada emissão. Posteriormente, procedeu-se à categorização de meios comunicativos (verbal, gestual, vocal, ação motora, verbal/gestual, vocal/gestual verbal/ação motora, vocal/ ação motora) e funções comunicativas. A categorização funcional foi baseada em estudos anteriores (PEREZ-PEREIRA; CONTI-RAMSDEN, 2001; FERNANDES, 2000; WETHERBY; RODRIGUEZ, 1992), resultando conseqüentemente numa detalhada identificação e descrição de 5 Categorias e 30 Subcategorias. Estas categorias e subcategorias foram definidas e submetidas, previamente, a análise

\footnotetext{
${ }^{4}$ A Revista Infantil PICOLÉ é de entretenimento e informação voltada para crianças de 5 a 12 anos de idade. Ela oferece atividades que estimulam a percepção visual, o vocabulário e a ortografia e faz parte da coleção Revistas Coquetel. http://www.coquetel.com.br/produtos.asp\#tit box8, acessado em dezembro de 2003.
} 
de conteúdo e semântica por para aferição. No caso do presente estudo os juizes foram fonoaudiólogos (professores e profissionais) com atuação efetiva na área de linguagem. Por meio desta categorização pode-se obter um perfil fidedigno do comportamento lingüístico das crianças participantes do estudo.

Cálculo do índice de fidedignidade: Por se tratar de um delineamento experimental intra-sujeitos, foi necessário verificar a concordância entre os observadores ou índice de fidedignidade, utilizando-se o CIF (Cálculo do Índice de Fidedignidade). Segundo Fagundes (1985) e Kazdin (1982), este índice é utilizado para verificar se há confiabilidade nos registros, minimizar a parcialidade de algum observador e confirmar a definição apurada do comportamento. Sendo assim, por se tratar de um sistema de classificação, os dados referentes ao desempenho comunicativo (tanto em situação livre como planejada), de quatro crianças (66\% da amostra) foram submetidos à análise de três juízes peritos na área de Fonoaudiologia (J1; J2 e J3). Essa amostra de participantes foi escolhida aleatoriamente (FAGUNDES, 1985; TAWNEY; GAST, 1984; KAZDIN, 1982). As filmagens desses participantes foram exibidas aos juízes que realizaram a categorização das funções, conforme procedimento do estudo. Após as análises classificatórias, feitas pelos juízes, foi calculado o índice de concordância (IC).

\section{Resultados}

1) Cálculo do índice de fidedignidade:

O índice de fidedignidade da medida adotada neste estudo foi obtido a partir do Índice de Concordância entre juizes (IC). Para a obtenção deste índice foi considerada a função comunicativa atribuída por cada um deles as categorias e subcategorias apresentadas e, também, a emitida pela pesquisadora (J4). Na Tabela 2 , podem ser observados os valores encontrados.

TABELA 2 - Resultados do cálculo do índice de concordância entre juízes.

\begin{tabular}{lcccc}
\hline \multicolumn{5}{c}{ Juízes } \\
\hline Situações & J 1 & J2 & J3 & J4 \\
\hline Livre & $92 \%$ & $88 \%$ & $88 \%$ & $86 \%$ \\
Planejada & $94,50 \%$ & $89 \%$ & $91 \%$ & $91 \%$ \\
M édia & $93,25 \%$ & $88,50 \%$ & $89,50 \%$ & $88,50 \%$ \\
\hline
\end{tabular}

A média do índice de concordância (IC), em relação aos dados das crianças, variou entre $88,5 \%$ a 93,5\%. Em função do alto índice de concordância encontrado denota-se alta precisão, isto é, a medida adotada foi precisa (TAWNEY; GAST, 1984; KAZDIN, 1982). 
2) Meios utilizados pelas crianças para emitir as funções comunicativas:

Nas Tabelas 3 e 4, logo abaixo, serão apresentados os meios utilizados pelas crianças para emitirem as funções comunicativas, em situações livre e planejada, respectivamente.

TABELA 3 - Meios utilizados pelas crianças para emitir as funções comunicativas em situação livre.

\begin{tabular}{|c|c|c|c|c|c|c|c|c|c|c|c|c|}
\hline \multirow[b]{2}{*}{ Meios } & \multicolumn{3}{|c|}{ Crianças cegas } & & \multicolumn{3}{|c|}{ Crianças com baixa visão } & \multicolumn{5}{|c|}{ Crianças com visão normal } \\
\hline & $\mathrm{CCF}$ & & $\mathrm{CCM}$ & & CBVF & & CBVM & & CVNF & & CVNM & \\
\hline Ação motora & 11 & $13 \%$ & 23 & $27 \%$ & 50 & $55 \%$ & 16 & $23 \%$ & 17 & $23 \%$ & 10 & $12 \%$ \\
\hline Gestual & 0 & $0 \%$ & 5 & $5,50 \%$ & 4 & $4 \%$ & 6 & $8,50 \%$ & 10 & $13 \%$ & 14 & $16 \%$ \\
\hline Vocal & 2 & $3 \%$ & 2 & $3 \%$ & 1 & $1 \%$ & 1 & $1 \%$ & 0 & $0 \%$ & 0 & $0 \%$ \\
\hline Verbal & 44 & $51 \%$ & 46 & $57 \%$ & 17 & $18 \%$ & 17 & $24 \%$ & 35 & $47 \%$ & 43 & $52 \%$ \\
\hline Verbal/ação motoı & 22 & $26 \%$ & 2 & $3 \%$ & 15 & $16 \%$ & 7 & $11 \%$ & 10 & $13 \%$ & 7 & $8 \%$ \\
\hline Verbal/gestual & 5 & $5,50 \%$ & 2 & $3 \%$ & 3 & $4 \%$ & 8 & $11,50 \%$ & 2 & $3 \%$ & 10 & $12 \%$ \\
\hline Vocal/ação motorá & 1 & $1,50 \%$ & 1 & $1,50 \%$ & 2 & $2 \%$ & 8 & $11,50 \%$ & 0 & $0 \%$ & 0 & $0 \%$ \\
\hline Vocal/gestual & 0 & $0 \%$ & 0 & $0 \%$ & 0 & $0 \%$ & 6 & $8,50 \%$ & 1 & $1 \%$ & 0 & $0 \%$ \\
\hline Total & 85 & $100 \%$ & 81 & $100 \%$ & 92 & $100 \%$ & 69 & $100 \%$ & 75 & $100 \%$ & 84 & $100 \%$ \\
\hline
\end{tabular}

Legenda: CCF - criança cega do sexo feminino; CCM - criança cega do sexo masculino; CBVF criança com baixa visão do sexo feminino; CBVM - criança com baixa visão do sexo masculino; CVNF - criança com visão normal do sexo feminino; CVNM - criança com visão normal do sexo masculino.

Nas duas situações, livre e planejada, verificou-se que o meio predominante na comunicação das crianças foi o verbal, embora isso não tenha ocorrido com a criança de baixa visão do sexo feminino (CBVF) em situação livre. Nessa referida situação, essa criança emitiu a maior parte $(55 \%)$ das funções comunicativas por meio de ações motoras. Mesmo somando-se o meio verbal (18\%) isolado aos outros que aparecem de modo simultâneo a ações motoras ou gestos, ou seja, verbal/ação motora (16\%) e verbal/gestual (4\%) o resultado final (38\%) não supera o meio ação motora.

Em relação às outras crianças, ainda em situação livre, observa-se que o meio verbal apresenta-se em $51 \%$ da comunicação de CCF (criança cega do sexo feminino), 57\% na comunicação de CCM, com 18\% na comunicação de CBVF (criança com baixa visão do sexo feminino) e em $24 \%$ das funções emitidas por CBVM (criança com baixa visão do sexo masculino). Na comunicação das crianças com visão normal, essa freqüência é de $47 \%$ e $52 \%$ respectivamente, para a criança do sexo feminino e masculino. Esses dados, por sua vez, confirmam os relatos das mães ao se referirem ao meio verbal como meio principal de comunicação das crianças. Por outro lado, os desempenhos foram bem diferentes em situação planejada. 
TABELA 4: Meios utilizados pelas crianças para emitir as funções comunicativas em situação planejada.

\begin{tabular}{|c|c|c|c|c|c|c|c|c|c|c|c|c|c|c|c|c|}
\hline \multirow[b]{3}{*}{ Meios } & \multicolumn{16}{|c|}{ Participantes } \\
\hline & \multicolumn{3}{|c|}{ Crianças cegas } & \multicolumn{5}{|c|}{ Crianças com b aixa visão } & \multicolumn{7}{|c|}{ Crianças com visão normal } & \\
\hline & $\mathrm{CCF}$ & & $\mathrm{CCM}$ & & CBVF & & CBVM & & $\mathrm{VNF}(\mathrm{CC}$ & & EVNM (C & & VNF ( & & $\mathrm{NM}($ & \\
\hline Ação motora & 9 & $12 \%$ & 18 & $26 \%$ & 35 & $37 \%$ & 26 & $21 \%$ & 10 & $9 \%$ & 13 & $13 \%$ & 8 & $9 \%$ & 11 & $11 \%$ \\
\hline Gestual & 0 & $0 \%$ & 0 & $0 \%$ & 1 & $2 \%$ & 9 & $8 \%$ & 2 & $2 \%$ & 6 & $6 \%$ & 0 & $0 \%$ & 7 & $7 \%$ \\
\hline Vocal & 8 & $11 \%$ & 0 & $0 \%$ & 3 & $3 \%$ & 0 & $0 \%$ & 0 & $0 \%$ & 0 & $0 \%$ & 0 & $0 \%$ & 0 & $0 \%$ \\
\hline Verbal & 26 & $35 \%$ & 36 & $51 \%$ & 35 & $37 \%$ & 46 & $37 \%$ & 67 & $62 \%$ & 62 & $61 \%$ & 48 & $48 \%$ & 49 & $51 \%$ \\
\hline Verbal/ação motora & 18 & $24 \%$ & 15 & $21,50 \%$ & 7 & $8 \%$ & 33 & $26 \%$ & 13 & $12 \%$ & 3 & $3 \%$ & 24 & $24 \%$ & 19 & $20 \%$ \\
\hline Verbal/gestual & 10 & $13,50 \%$ & 1 & $1,50 \%$ & 8 & $9 \%$ & 8 & $7 \%$ & 13 & $12 \%$ & 18 & $17 \%$ & 17 & $18 \%$ & 11 & $11 \%$ \\
\hline Vocal/ação motora & 3 & $4,50 \%$ & 1 & $1,50 \%$ & 2 & $2 \%$ & 0 & $0 \%$ & 0 & $0 \%$ & 0 & $0 \%$ & 0 & $0 \%$ & 0 & $0 \%$ \\
\hline Vocal/gestual & 0 & $0 \%$ & 0 & $0 \%$ & 2 & $2 \%$ & 1 & $1 \%$ & 3 & $3 \%$ & 0 & $0 \%$ & 1 & $1 \%$ & 0 & $0 \%$ \\
\hline Total & 74 & $100 \%$ & 71 & $100 \%$ & 93 & $100 \%$ & 123 & $100 \%$ & 108 & $100 \%$ & 102 & $100 \%$ & 98 & $100 \%$ & 97 & $100 \%$ \\
\hline
\end{tabular}

Legenda: CCF - criança cega do sexo feminino; CCM - criança cega do sexo masculino; CBVF criança com baixa visão do sexo feminino; CBVM - criança com baixa visão do sexo masculino; CVNF - criança com visão normal do sexo feminino; CVNM - criança com visão normal do sexo masculino.

Observa-se na Tabela 4 que o meio predominante na comunicação das crianças continuou sendo o verbal, fazendo-se a ressalva em relação à criança com baixa visão do sexo feminino (CBVF) que embora tenha emitido o meio verbal (37\%) com mesma freqüência que ação motora (37\%), diferentemente da situação de interação livre, a soma ( $54 \%$ ) dos meios verbal (37\%), verbal/ação motora ( $8 \%$ ) e verbal/ gestual (9\%) supera a freqüência do meio ação motora (37\%) isolado.

Ainda em situação planejada, os desempenhos das outras crianças foram os seguintes: o meio verbal aparece em 35\% das emissões de CCF (criança cega do sexo feminino). É importante ressaltar que houve também um predomínio desse meio na comunicação dessa criança de modo simultâneo a ações motoras ( $24 \%)$ e gestos (13,5\%). O meio verbal apareceu em 51\% das emissões de CCM e, também, em 37\% das funções emitidas por CBVM (criança com baixa visão do sexo masculino). Na comunicação das crianças com visão normal essa freqüência foi de $62 \%$ para CVNF e $61 \%$ para CVNM em situação planejada CC e de $48 \%$ e $51 \%$ em situação planejada $B V$.

Quanto ao meio vocal, é interessante notar que ele praticamente não aparece na comunicação das crianças ou, se aparece, não chega a ser de maneira significativa. Apenas na comunicação da criança cega do sexo feminino (CCF) em situação planejada houve uma presença com maior freqüência (16\%), mesmo assim, tratou-se de situações, nas quais a mãe foi responsiva, o que indicou inteligibilidade por parte dela. 
3) Funções comunicativas emitidas pelas crianças:

No que se refere aos tipos e freqüência das funções comunicativas, nas Tabelas 5, 6 e 7, a seguir, serão apresentados os desempenhos tanto das crianças como de suas mães, a fim de que a discussão pudesse ser norteada também em relação ao equilíbrio da interação dessas díades.

TABELA 5 - Tipos e freqüência de funções comunicativas emitidas pelas crianças e suas mães durante a interação em situação livre.

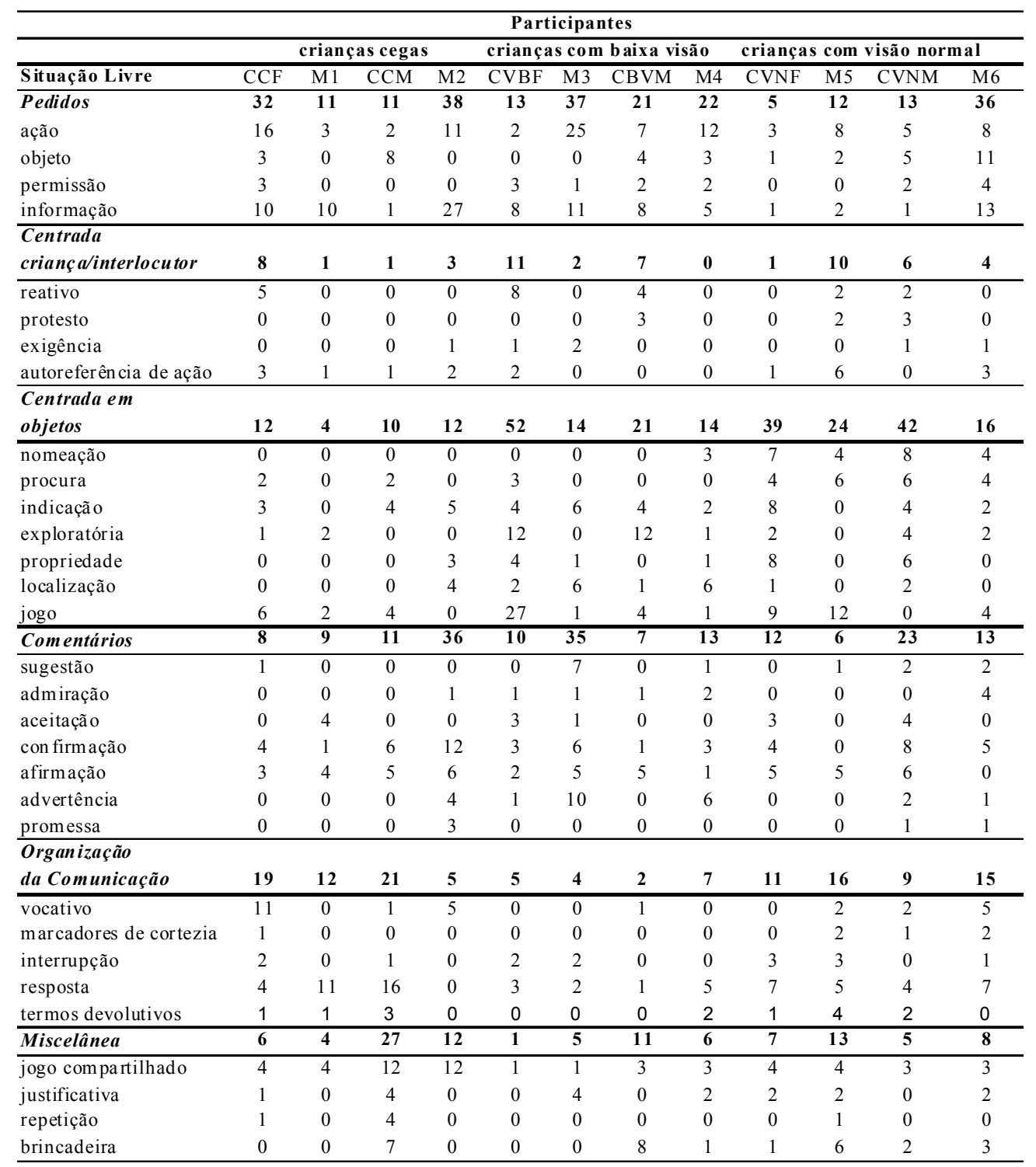

Legenda: CCF - criança cega do sexo feminino; CCM - criança cega do sexo masculino; CBVF criança com baixa visão do sexo feminino; CBVM - criança com baixa visão do sexo masculino; CVNF - criança com visão normal do sexo feminino; CVNM - criança com visão normal do sexo masculino; M: mães. 
Quanto às outras díades, ainda em situação livre de interação, destacase a freqüência de pedidos de informação (27) de M2 e a freqüência de respostas (16) de CCM. Esses dados podem indicar uma interação mantida mais por M2 onde CCM ocupa pouco espaço comunicativo, ou seja, a mãe pergunta bastante cabendo à criança apenas responder a essas perguntas. Sendo assim, o desempenho da criança pode estar vinculado às oportunidades de emissão que o interlocutor oferece na situação de interação.

Por outro lado, essa díade apresenta uma freqüência considerável de jogos compartilhados (12). Destaca-se também a freqüência de repetições (4) na comunicação de CCM, quando comparada à das outras crianças: CCF (1) e (0) para CBVF, CBVM, CVNF e CVNM.

Em situação planejada CC, parece ocorrer um equilíbrio na interação entre todas as díades, porém alguns dados indicados na Tabela 6 merecem destaque: a alta freqüência da função exploratória (8) na comunicação de CCM e o alto índice de indicações, tanto de M2 (7), quanto de M1 (6).

TABELA 6 - Tipos e freqüência de funções comunicativas emitidas pelas crianças e suas mães durante a interação em situação planejada CC.

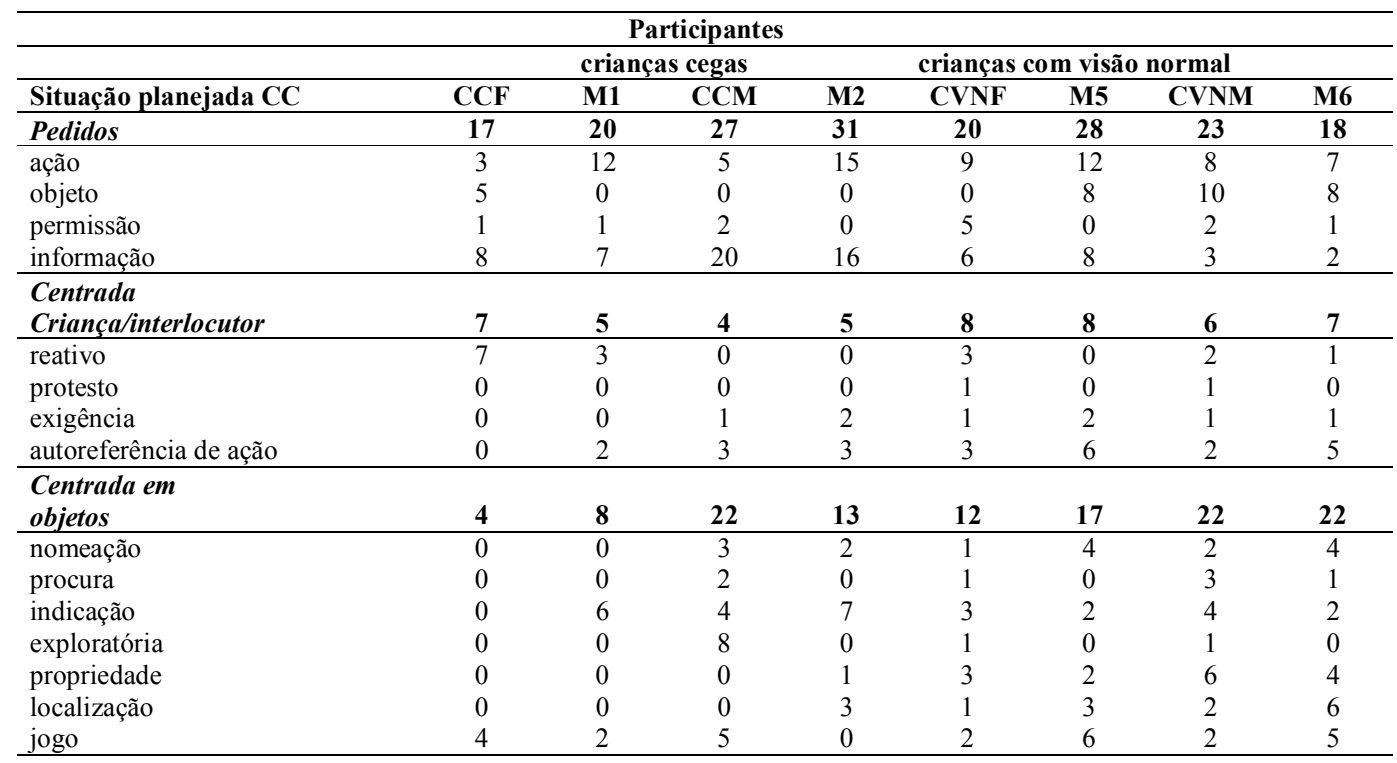


TABELA 6 - Tipos e freqüência de funções comunicativas emitidas pelas crianças e suas mães durante a interação em situação planejada CC. (continuação)

\begin{tabular}{|c|c|c|c|c|c|c|c|c|}
\hline \multicolumn{9}{|c|}{ Participantes } \\
\hline & & \multicolumn{2}{|c|}{ crianças cegas } & & \multicolumn{3}{|c|}{ crianças com visão normal } & \multirow[b]{2}{*}{ M6 } \\
\hline Situação planejada $\mathrm{CC}$ & CCF & M1 & CCM & M2 & CVNF & M5 & CVNM & \\
\hline Comentários & 10 & 19 & 6 & 21 & 24 & 29 & 9 & 19 \\
\hline sugestão & 0 & 5 & 0 & 2 & 3 & 6 & 1 & 4 \\
\hline admiração & 0 & 0 & 0 & 0 & 0 & 2 & 0 & 1 \\
\hline aceitação & 3 & 1 & 2 & 0 & 4 & 4 & 2 & 0 \\
\hline confirmação & 5 & 5 & 3 & 8 & 7 & 4 & 1 & 2 \\
\hline afirmação & 2 & 3 & 1 & 6 & 6 & 9 & 5 & 11 \\
\hline advertência & 0 & 5 & 0 & 4 & 4 & 2 & 0 & 1 \\
\hline promessa & 0 & 0 & 0 & 1 & 0 & 2 & 1 & 0 \\
\hline $\begin{array}{l}\text { Organização } \\
\text { da Comunicação }\end{array}$ & 6 & 6 & 7 & 14 & 12 & 4 & 6 & 12 \\
\hline vocativo & 0 & 0 & 0 & 4 & 4 & 2 & 0 & 3 \\
\hline marcadores de cortesia & 0 & 0 & 0 & 0 & 0 & 0 & 1 & 0 \\
\hline interrupção & 0 & 0 & 1 & 1 & 0 & 0 & 2 & 3 \\
\hline resposta & 5 & 6 & 5 & 3 & 8 & 2 & 3 & 4 \\
\hline termos devolutivos & 1 & 0 & 1 & 6 & 0 & 0 & 0 & 2 \\
\hline Miscelânia & 28 & 19 & 7 & 9 & 42 & 26 & 32 & 24 \\
\hline jogo compartilhado & 12 & 12 & 4 & 4 & 24 & 24 & 18 & 18 \\
\hline justificativa & 2 & 7 & 0 & 5 & 4 & 0 & 6 & 4 \\
\hline repetição & 8 & 0 & 3 & 0 & 6 & 0 & 0 & 0 \\
\hline brincadeira & 6 & 0 & 0 & 0 & 8 & 2 & 8 & 2 \\
\hline
\end{tabular}

Legenda: CCF - criança cega do sexo feminino; CCM - criança cega do sexo masculino; CVNF criança com visão normal do sexo feminino; CVNM - criança com visão normal do sexo masculino; M: mães.

Contudo, destaca-se a baixa freqüência de jogos compartilhados (4) na comunicação dessa díade (CCM/M2), quando comparada a das outras díades: CCF/M1 (12); CVNF/M5 (24) e CVNM/M6 (18). Embora se tratasse de uma atividade a ser realizada em conjunto, esses resultados indicam que pode ter havido uma separação de tarefas entre essa díade. Deve-se, então, atentar para a questão do equilíbrio da interação versus preocupação da mãe em relação ao desempenho da criança na atividade. Novamente, destaca-se um alto índice de repetições (8), porém tratando-se da comunicação de CCF, muito embora tal comportamento ocorra também com CCM (3) e CVNF (6).

Em situação planejada BV, os dados apresentados na Tabela 7 indicam também uma semelhança geral, destacando, por sua vez, o alto índice de pedidos em relação à comunicação de M3 (35) e M4 (44). 
TABELA 7 - Tipos e freqüência de funções comunicativas emitidas pelas crianças e suas mães durante a interação em situação planejada BV.

\begin{tabular}{|c|c|c|c|c|c|c|c|c|}
\hline \multirow[b]{3}{*}{$\overline{\text { Situação planejada BV }}$} & \multicolumn{8}{|c|}{ Participantes } \\
\hline & \multicolumn{4}{|c|}{ crianças com baixa visão } & \multicolumn{4}{|c|}{ crianças com visão normal } \\
\hline & CVBF & M3 & CBVM & M4 & CVNF & M5 & CVNM & M6 \\
\hline$\overline{\text { Pedidos }}$ & 25 & 35 & 35 & 44 & 17 & 31 & 15 & 27 \\
\hline ação & 6 & 12 & 17 & 22 & 3 & 12 & 7 & 10 \\
\hline objeto & 4 & 0 & 6 & 0 & 6 & 8 & 5 & 7 \\
\hline permissão & 4 & 4 & 4 & 3 & 5 & 6 & 1 & 1 \\
\hline informação & 11 & 19 & 8 & 19 & 3 & 5 & 2 & 9 \\
\hline \multicolumn{9}{|l|}{ Centrada } \\
\hline criança/interlocutor & 11 & 7 & 11 & 3 & 6 & 5 & 4 & 6 \\
\hline reativo & 5 & 1 & 1 & 2 & 0 & 2 & 1 & 1 \\
\hline protesto & 0 & 0 & 3 & 0 & 3 & 0 & 0 & 0 \\
\hline exigência & 1 & 0 & 0 & 0 & 0 & 1 & 2 & 1 \\
\hline autoreferência de ação & 5 & 6 & 7 & 1 & 3 & 2 & 1 & 4 \\
\hline \multicolumn{9}{|l|}{ Centrada em } \\
\hline objetos & 34 & 46 & 46 & 27 & 24 & 27 & 15 & 31 \\
\hline nomeação & 0 & 7 & 5 & 6 & 0 & 4 & 1 & 3 \\
\hline procura & 4 & 0 & 5 & 0 & 2 & 2 & 1 & 3 \\
\hline indicação & 2 & 25 & 4 & 9 & 3 & 2 & 2 & 1 \\
\hline exploratória & 11 & 0 & 5 & 1 & 11 & 2 & 4 & 3 \\
\hline propriedade & 1 & 0 & 0 & 1 & 3 & 4 & 2 & 7 \\
\hline localização & 0 & 9 & 0 & 5 & 1 & 5 & 3 & 2 \\
\hline jogo & 16 & 5 & 27 & 5 & 4 & 8 & 2 & 12 \\
\hline Comentários & 10 & 29 & 16 & 29 & 16 & 22 & 10 & 33 \\
\hline sugestão & 0 & 2 & 0 & 4 & 0 & 2 & 1 & 6 \\
\hline admiração & 3 & 4 & 1 & 1 & 0 & 4 & 0 & 4 \\
\hline aceit ação & 0 & 0 & 4 & 0 & 5 & 2 & 2 & 1 \\
\hline confirmação & 1 & 2 & 0 & 4 & 4 & 2 & 1 & 6 \\
\hline afirmação & 5 & 6 & 8 & 6 & 4 & 9 & 5 & 13 \\
\hline advertência & 1 & 15 & 3 & 23 & 3 & 2 & 0 & 3 \\
\hline promessa & 0 & 0 & 0 & 1 & 0 & 1 & 1 & 0 \\
\hline \multicolumn{9}{|l|}{$\overline{\text { Organização }}$} \\
\hline da Comu nica ção & 11 & 14 & 5 & 6 & 18 & 13 & 10 & 14 \\
\hline vocativo & 1 & 0 & 0 & 0 & 2 & 3 & 1 & 2 \\
\hline marcadores de cortezia & 1 & 0 & 0 & 0 & 0 & 2 & 0 & 0 \\
\hline inter rupção & 3 & 10 & 1 & 1 & 6 & 2 & 1 & 3 \\
\hline resposta & 4 & 3 & 4 & 4 & 11 & 6 & 6 & 8 \\
\hline termos devolutivos & 2 & 1 & 0 & 1 & 0 & 0 & 2 & 1 \\
\hline Miscelânea & 6 & 5 & 27 & 15 & 1 & 10 & 11 & 11 \\
\hline jogo compartilhado & 4 & 4 & 12 & 12 & 1 & 1 & 3 & 3 \\
\hline justificativa & 1 & 1 & 4 & 3 & 0 & 6 & 0 & 5 \\
\hline repetição & 1 & 0 & 4 & 0 & 0 & 0 & 0 & 1 \\
\hline brinca deira & 0 & 0 & 7 & 0 & 0 & 3 & 8 & 2 \\
\hline
\end{tabular}

Legenda: CBVF - criança com baixa visão do sexo feminino; CBVM - criança com baixa visão do sexo masculino; CVNF - criança com visão normal do sexo feminino; CVNM - criança com visão normal do sexo masculino; M: mães. 
Conforme apontado anteriormente, em relação às mães das crianças cegas, estas também emitiram um alto índice de indicações: M3 (25) e M4 (9). Em relação às crianças a alta freqüência de jogos emitidos por CBVF (27) e por CBVM (16) confirma o uso de ações motoras em detrimento do meio verbal, dados também já discutidos. Ao serem analisados os diretivos maternos na comunicação entre crianças deficientes visuais e crianças com visão normal, pode-se concluir que, embora não houvesse diferenças significativas entre a interação, a análise pragmática do estudo demonstrou que a alta freqüência do uso de comportamentos não verbais por parte das crianças poderia estar relacionada aos comportamentos diretivos das mães.

De maneira contrária à situação planejada CC, agora, ou seja, na situação planejada $\mathrm{BV}$, por se tratar de uma atividade de pintura e, portanto, de caráter individual, destaca-se o considerável índice de jogos compartilhados (12) em relação à díade $\mathrm{CBVF} / \mathrm{M} 3$, indicando um possível auxílio motor da mãe na atividade.

\section{DISCUSSÃo}

De maneira geral, os resultados apresentados nas Tabelas 3 e 4 indicaram que há um predomínio do meio verbal na comunicação das crianças, mesmo que em algumas situações esse meio tenha sido emitido de maneira simultânea a um gesto ou ação motora.

A literatura referente ao desenvolvimento normal da linguagem, aponta que o surgimento das verbalizações em detrimento dos gestos ocorre por volta dos 18 meses, sendo que antes desse período as mesmas são normalmente acompanhadas de gestos, como apontar, dentre outros. Nessa fase, ou seja, por volta dos 18 meses, as crianças tendem a substituir os gestos e vocalizações pelas verbalizações, sendo que próximo aos 24 meses a linguagem dessas crianças passa a obter características cada vez mais complexas (WETHERBY; RODRIGUES, 1992; LAUNAY, 1989; OPPENHEIMER et al., 2001).

Embora tenham aparecido alguns gestos na comunicação da criança cega do sexo masculino (CCM) em situação livre, foi possível observar que a freqüência desse meio foi muito baixa de maneira geral. Essa ausência pode ser atribuída à própria ausência da informação visual. Ainda em relação ao meio verbal é consenso na literatura especializada que a linguagem oral é a forma fundamental na comunicação dessas crianças, seja para obter informações do ambiente, regular ou planejar seus comportamentos (PÉREZ-PEREIRA; CASTRO, 1992; ERIN, 1986).

Muitos autores enfatizam que o desenvolvimento da linguagem, durante o período pré-escolar, ocorre de maneira uniforme e progressiva com aquisição de novas habilidades, a fim de que estas sejam aperfeiçoadas e facilitem o processo de aprendizagem como um todo. Dessa forma, há o início dos processos comunicativos desde a lalação, balbucio, vocalizações, vocalizações simultâneas aos gestos e finalmente as verbalizações, sendo que estas últimas vão sendo aperfeiçoadas de acordo com a idade da criança (LAUNAY, 1989). 
Sendo assim, reafirma-se que os dados obtidos no presente estudo, em relação aos meios utilizados pelos participantes, para emitir as funções comunicativas, apontaram um desempenho esperado para a idade das crianças, embora algumas particularidades descritas mereçam um maior destaque, como é o caso do uso elevado do meio ação motora pelas crianças com baixa visão. Estas indicações podem ser observadas por meio dos dados contidos nas Tabelas 3 e 4 . Assim sendo, as crianças deficientes visuais usaram de maneira considerável esse meio em suas emissões, o que não ocorreu com as crianças com visão normal. Em situação planejada esse uso chega a ser de $37 \%$ na comunicação da criança com baixa visão do sexo feminino (CBVF - Tabela 4).

Uma explicação para tal dado pode ser o uso necessário do sentido tátil por tais crianças. E embora as crianças com baixa visão tenham resíduo visual elas, na maioria das vezes, precisam aproximar os objetos dos olhos para explorálos ou nomeá-los. Em relação às crianças cegas, esse uso é mais evidente, pela falta da visão, ou seja, o reconhecimento principalmente de objetos dá-se por meio de ações motoras.

As implicações desses dados refletem em questões educacionais e terapêuticas que vão desde adaptação de materiais de uso rotineiro em sala de aula - tratando-se de um assunto bastante explorado pela literatura até o momento - à maneira como deve ser veiculada a comunicação com essa população específica. Nesse sentido, é preciso enfatizar que um atendimento voltado para essas crianças com deficiência visual, principalmente em nível de estimulação do processo de aquisição e desenvolvimento da linguagem, deverá ser direcionado para exploração tátil-cinestésica de objetos de modo funcional. Sendo assim, os objetos oferecidos a elas deverão estar inseridos em uma situação na qual possam obter seu significado por meio do seu uso, atentando-se principalmente para que estes objetos estejam próximos da criança.

Diferentemente da criança com visão normal, que pode simplesmente observar esse uso, não necessariamente tocando em objetos, quando a ação está sendo realizada pelo interlocutor. Isso também significa dizer que o profissional deverá observar a maneira como ele se comportará em relação à proximidade entre ele e a criança deficiente visual. Posto que os aspectos apontados são extremamente importantes, estes devem ser considerados em relação ao trabalho educacional e terapêutico com essa população, isto é, com as crianças deficientes visuais.

Em relação à situação livre de interação, os dados obtidos (Tabela 5) chamam atenção para o número de funções emitidas por CCF e sua mãe (M1). Enquanto CCF emitiu na interação 85 funções comunicativas, M1 emitiu apenas 41. Uma explicação para tais resultados, pode ser o maior número de iniciativas de comunicação por parte dessa criança, haja vista o número de pedidos de ação (16) de CCF. Os estudos que analisaram a interação de crianças cegas e suas mães, apesar de apontarem maiores quebras na interação dessas díades e um número de enunciados diferentes entre mãe e criança, não apresentaram dados muito 
discrepantes em relação à forma de interação de crianças com visão normal (KEKELIS; ANDERSEN, 1984; KEKELIZ; PRINZ, 1996). Alguns estudos também encontraram um maior equilíbrio em relação ao número de enunciados entre a díade da criança com visão normal ao compararem a comunicação verbal entre crianças deficientes visuais e crianças com visão normal (PEREZ-PEREIRA; CONTIRAMSDEN, 2001).

É importante ressaltar que não só do interlocutor depende o desempenho comunicativo geral da criança. Por exemplo, em situação livre, as atividades foram escolhidas pelas mães e pelas crianças, diferindo-se completamente em relação a todas as díades. Algumas crianças, talvez, tenham emitido menos funções em tal situação por causa do jogo ou da brincadeira que escolheram para interagir com suas mães. Por isso, a necessidade de se variar o contexto para que não se corresse o risco de serem feitas análises simplistas de um só contexto.

Quanto aos dados contidos na Tabela 6, apreende-se a possibilidade de que comportamentos maternos sejam emitidos no sentido de auxiliar a criança durante a atividade para que elas possam ter êxito. Nesse sentido, podem ser analisadas também a presença das funções localização, propriedades e nomeação na comunicação de M2.

Conforme exposto em alguns estudos existe uma necessidade clara da realização de uma análise minuciosa dos diretivos maternos na situação de interação, particularmente em relação às crianças cegas, por se tratar de descrições importantes. Pesquisadores destacam ainda a necessidade desses diretivos para que a criança obtenha informações importantes do contexto e se sinta preparada para emitir suas respostas (PEREZ-PEREIRA; CONTI-RAMSDEN, 2001).

\section{CONCLUSÃo}

De modo geral, os resultados do presente estudo, embora não permitam generalizações em função da pequena amostra, evidenciam importantes aspectos acerca da linguagem das crianças deficientes visuais durante a interação com suas mães, contribuindo de modo significativo para futuras intervenções.

Neste sentido merece destaque o uso de ações motoras em detrimento do meio verbal manifestado pelas crianças com baixa visão, em função do seu próprio déficit visual. Posta esta conduta, emergem implicações educacionais principalmente relacionadas à necessidade de ser estimulada a linguagem oral dessas crianças, haja vista o importante papel da mesma na interação social, assim como mediadora de todo o processo de aprendizagem desta população.

Uma outra importante implicação do estudo refere-se à análise dos comportamentos diretivos das mães das crianças deficientes visuais. Muito embora não exista consenso na literatura acerca de tais comportamentos, nossos achados sinalizam a necessidade de esclarecimento e orientação das mães sobre a 
fundamental importância do equilíbrio da comunicação entre os interlocutores durante a interação, pois em alguns casos, como foi apontado nos resultados, houve uma diferença significativa entre o número de emissões das mães em relação ao das crianças, durante a interação, o que indicou um possível desequilíbrio nessa interação. Pode ser que algumas mães não estivessem atentas em relação ao tempo que deveriam dar para a criança, antes de solicitarem uma outra informação. No presente caso, o estabelecimento desse equilíbrio seria resultante de um maior espaço comunicativo da criança, durante a interação, o que viria a favorecer maiores iniciativas de diálogo por parte das crianças portadoras de deficiência visual.

Adicionalmente, merece destaque a adequação e viabilidade da metodologia empregada no estudo, principalmente em relação às análises de comportamentos não verbais da amostra estudada via protocolo de caracterização elaborado e aferido pelos juizes.

Enfim, dentro de suas possibilidades informativas, os resultados do presente estudo permitiram constatar que não se pode falar em distúrbios de linguagem em crianças deficientes visuais. Contudo, aponta-se como importante a atenção especial que deve ser dada ao período inicial de desenvolvimento dessas crianças, principalmente no que se refere à forma como suas mães interagem com elas. Esta interação durante a fase pré-linguística é primordial para a aquisição da linguagem e seu desenvolvimento geral. É nessa fase que a mãe, interlocutora principal da criança, dará significado tanto às situações como aos objetos. Dessa forma, não se pode negar a necessidade dessa população ser assistida desde o seu nascimento, não só em função do acompanhamento em relação às mudanças que podem ocorrer no sistema visual, no caso das crianças com baixa visão, no que tange às adaptações e recursos ópticos, como também a respeito dos aspectos cognitivos e de linguagem.

No sentido de minimizar deficiências e em caráter mais amplo e preventivo, salienta-se aqui a importância da intervenção precoce por meio de um programa articulado, a fim de que o desenvolvimento dessas crianças seja promovido, mesmo com a presença de tal alteração.

Finalizando, pretendeu-se com este estudo oferecer uma contribuição metodológica ao estudo do tema sobre aquisição da linguagem em crianças com deficiência visual, compartilhando algumas evidências baseadas na análise do desempenho pragmático da linguagem e interação materna. 


\section{REFERÊNCIAS}

ANDERSEN, E.S.; DUNLEA, A.; KEKELIS, L. Blind children's language: resolving some differences, Journal of Child Language, v.11, p. 645-664, 1984.

BAIRD, S.M.; MAYFIELD, P.; BAKER, P. Mothers' interpretations of the behavior of their infants with visual and other impairments during interactions, Journal of Visual Impairment E Blindness, v. 91, n. 5, p. 467-483, 1997.

BRAGA, T.M.S.; OLIVEIRA, J.P. Análise da Linguagem oral de uma criança com deficiência visual. In: MANZINI, E. (org.). Educação Especial: temas atuais. Marília: Unesp Marília Publicações, p. 21-33, 2000.

DIMCOVIC, N.; TOBIN, M.J. The use of language in simple classification tasks by children who are blind, Journal of Visual Impairment \& Blindness, v. 89, n. 5, p. 448-459, 1995.

ERIN, J.N. Frequencies and types of questions in the language of visually impairment children, Journal of Visual Impairment \& Blindness, p. 670-674, 1986.

FAGUNDES, A.J.F.M. Descrição, definição e registro do comportamento. Edicon, São Paulo, 1985.

FERNANDES, F.D.M. Pragmática - (parte D). In: ANDRADE, C.R.F.; BEFI-LOPES, S.D.M.; FERNANDES, F.D.M.; WERTZNER, H.F. A.B.F.W. Teste de Linguagem Infantil: Nas Áreas de Fonologia, Vocabulário, Fluência e Pragmática. São Paulo: Pró-fono editora, $1^{\text {a }}$ edição, 2000.

FINELLO, M.K.; HANSON, N.H.; KEKELIS, L. Cognitive focus: developing cognition concepts and language in young blind and visually impaired children. In: POGROUND, RL; FAZZI, L.D.; LAMPERT, J.S. (orgs.). Early focus: working with young blind and visually impaired children and their families. New York: American foundation for the blind; 1994.

HUGHES, M.; DOTE-KWAN, J.; DOLENDO; J. Characteristics of maternal directiveness and responsiveness with young children with visual impairments, Child Care Health Development, v. 25, n. 4, p. 345-353, 1999.

KAZDIN, A.E. Single-Case research designs: methods for clinical and applied settings. Oxford University, New York, 1982.

KEKELIS, L.S.; ANDERSEN, E.S. Family communication styles and language development, Journal of Visual Impairment \& Blindness, v. 78, n. 2, p. 54-65, 1984.

KEKELIS, L.S.; PRINZ, P.M. Blind and sighted children with their mothers: the development of discourse skills, Journal of Visual Impairment \& Blindness, v. 90, n. 5, p. 423-436, 1996.

LAUNAY, C. Desenvolvimento normal da linguagem. In: LAUNAY, C.; MAISSONY; BOREL, S. (orgs.). Distúrbios da linguagem da fala e da voz na infância. São Paulo: Roca; p. 1729, 1989.

MILLS, A. Incapacitação visual. In: BISHOP, D.V.M.; MULFORD, R.C. (orgs). Aquisiçãao e desenvolvimento da linguagem em circunstâncias excepcionais. Porto Alegre: Artmed, p. 203224, 2002.

OPPENHEIMER, F.; ARAÚJO, A.A.; MARQUES, V.V.; AZEVEDO, M.F. Caracterização da emissão oral e da compreensão de ordens verbais em crianças de creches municipais. Temas sobre desenvolvimento, v. 10, n. 56, p. 20-25, 2001. 
PEREZ-PEREIRA, M.; CASTRO, J. Pragmatic functions of blind and sighted children's language: a twin case study, First Language, v. 12, p. 17-37, 1992.

PEREZ-PEREIRA, M.; CONTI-RAMSDEN, G. The use of directives in verbal interactions between blind children and their mothers, Journal of Visual Impairment $\mathcal{E}$ Blindness, v. 95, n. 3, p. 133-149, 2001.

SCHERMANN, L. Considerações sobre a interação mãe-criança e o nascimento pré-termo, Temas em Psicologia da SBP, v. 9, n. 1, p. 55-61, 2001.

SÍGOLO, S.R.R.L. Análise da interação mãe-criança com atraso de desenvolvimento no segundo ano de vida. Tese (doutorado) - Instituto de Psicologia, Universidade de São Paulo, São Paulo, 1994.

TAWNEY, J.W.; GAST, D.L. Single Subject Research in Special Education. Bill \& Towell Company, London, 1984.

WETHERBY, A.M.; RODRIGUEZ, G.P. Measurement of communicative intentions in normally developing children during structure and unstructured contexts, Journal Speech Hearing and Research, v. 35, n. 1, p. 130-138, 1992.

Recebido em 16/06/2005

Reformulado em 21/11/2005

Aprovado em 22/12/2005 